Pure \& Appl. Chem., Vo1. 49, pp. 701-716. Pergamon Press, 1977. Printed in Great Britain.

\title{
EFFECTS OF ORBITAI VACANCIES IN BORON COMPOUNDS
}

\author{
William N. Lipscomb \\ Department of Chemistry, Harvard University, \\ Cambridge, Massachusetts 02138, USA
}

\begin{abstract}
Addition of $\mathrm{H}_{2}$ to $\mathrm{BH}_{3}$ yields $\mathrm{BH}_{5}$, which is shown to be of $\mathrm{C}_{\mathbf{s}}$ symmetry. Rearrangement mechanisms and hydrogen loss have been examined.
\end{abstract}

Intermediates such as $\mathrm{B}_{3} \mathrm{H}_{7}$ and $\mathrm{B}_{4} \mathrm{H}_{8}$ have been predicted to have vacant orbital structures in which the stability gained by filling that orbital is balanced by strain in converting a terminal hydrogen to a bridge hydrogen. Other factors, such as hyperconjugative interactions and boron framework distortions are of importance. These factors have been examined also in bridge hydrogen asymmetries and distortions from regular geometry, in the light of vacant orbital contributions to valence structures of known boranes and carboranes.

Localization procedures have refined the concepts of where an open three-center bond is useful, where single bond donation becomes important, where fractional bonds occur, and where a more complex description can usefully replace a large number of valence structures.

\begin{abstract}
Vacant orbital contributions have also been used to guess where ligand (e.g. $\mathrm{H}^{-}$) attack may occur, and at which pair of adjacent boron atoms $\mathrm{BH}_{3}$ may be expected to add. A study of diborane formation indicates favoritism for simultaneous $\mathrm{H} \cdot \mathrm{B}$ and $\mathrm{B}$...H reaction of compounds of the two distinct $\mathrm{BH}_{3}$ reactants. Reactions of $\mathrm{BH}_{3}$ with higher hydrides, and of higher hydrides with each other may be expected to follow this principle.
\end{abstract}

\section{VACANT ORBITALS IN TRANSIENT SPECIES}

$\mathrm{BH}$

$\bar{A}$ prototype of the $\mathrm{BH}$ units in polyhedral molecules, the diatomic $\mathrm{BH}$ molecule has all of its electrons paired $\left(I_{\Sigma_{+}}\right)$. Nevertheless, it is paramagnetic. The magnetic susceptibility, $X=18.7 \mathrm{ppm}$ (1), is the temperature-independent type, and arises largely from excitations from the filled $3 \sigma$ level. This unusual property is a forewarning that magnetic shielding in the boron hydrides and carboranes have large, sometimes dominating, contributions from the paramagnetic term. The chemistry of this unstable species has not been studied, but would probably be very interesting.

$\mathrm{BH}_{3}$

Known as a reaction intermediate in diborane pyrolysis and other reactions, this molecule has a vacant orbital which cannot be filled by a molecular distortion. Adducts to Lewis bases have stabilities correlating with bond distance (2). It has been isolated in a matrix (3) at low temperatures, from pyrolysis of $\mathrm{BH}_{3} \mathrm{CO}$. Theoretical studies are consistent with the planar $D_{3 h}$ structure. We now turn to a very weak adduct between $\mathrm{BH}_{3}$ and $\mathrm{H}_{2}$.

$\mathrm{BH}_{5}$

When $\mathrm{BH}_{4} \mathrm{D}$ is produced by reaction (4) of $\mathrm{BH}_{4}{ }^{-}$with $\mathrm{D}_{3} \mathrm{O}^{+}$below $\mathrm{pH} 12$, about 958 of the hydrogen loss occurs as HD. This interesting observation implies either (a) that the $\mathrm{D}^{+}$becomes equivalent to only one resident $\mathrm{H}$ atom, or

(b) that the $\mathrm{D}$ remains unique and is lost when $\mathrm{BH}_{4} \mathrm{D}$ decomposes ( $\mathrm{A}$ candidate for this second possibility is that $D$ remains at the apex of tetragonal 
pyramidal $\left.\mathrm{BH}_{4} \mathrm{D}\right)$. We shall strongly favor the first possibility (a). First we examine geometries for $\mathrm{BH}_{5}$ (Fig. 1), then internal rearrangements, and

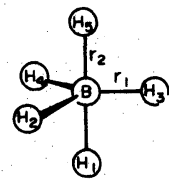

(a) $D_{3 h}$

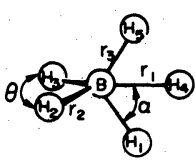

(c) $\mathrm{C}_{2 \mathrm{v}}$

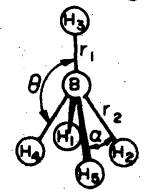

(b) $\mathrm{C}_{4 \mathrm{~V}}$

Fig. 1. Four plausible structures for $\mathrm{BH}_{5}$ : (a) $\mathrm{D}_{3 \mathrm{~h}}$, where $\mathrm{H}_{1} \mathrm{BH}_{5}$ is collinear, $r_{1}=$ 2.252 au and $r_{2}=2.280$ au; (b) $C_{4 v}$ with $\mathrm{H}_{3} \mathrm{~B}$ along the four-fold axis, $r_{1}=2.172$ au, $r_{2}=2.287$ au, $\theta=117.3^{\circ}, \alpha=77.9^{\circ}$; (c) $\mathrm{C}_{2 \mathrm{v}}$ where the two-fold axis is along $\mathrm{H}_{4} \mathrm{~B}, \mathrm{r}_{1}=2.492, \mathrm{r}_{2}=2.191$ au, $\mathrm{r}_{3}=$ 2.370 au, $\theta=123.00, \alpha=56.00$;

(d) $\mathrm{C}_{\mathbf{S}}$ (I and III) where $\mathrm{H}_{1} \mathrm{~B}$ lies in the symmetry plane: $r_{1}=r_{2}=r_{3}=2.280 \mathrm{au}$, $\theta=106.8^{\circ}, \alpha=46.6^{\circ}, \beta=116.4^{\circ}$ for $C_{s}(I)$, and $r_{1}=2.192$ au, $r_{2}=2.205 \mathrm{au}$, $r_{3}=2.807 \mathrm{au}, \theta=115.4^{\circ}, \alpha=32.1^{\circ}$, $\beta=117.4^{\circ}$ for $C_{S}$ (III).

then ask which hydrogens are lost as $\mathrm{H}_{2}$ from the theoretical point of view. At the 431G (SCF) level, energies in au are -27.386 for $D_{3 h},-27.403$ for $C_{4 v},-27.423$ for $C_{2 v},-27.427$ for $C_{S}(I),-27.454$ for $C_{s}$ (III), and -27.476 for $\mathrm{BH}_{3}+\mathrm{H}_{2}$. While the $\mathrm{C}_{\mathrm{s}}$ (III) structure is the most "stable," it is not in a minimum at the SCF level, where $\mathrm{BH}_{5}$ is unstable with respect to $\mathrm{BH}_{3}+\mathrm{H}_{2}$. Our estimate (5) of corrections for electron correlation predicts only marginal stability for $\mathrm{BH}_{5}$ (relative to $\mathrm{BH}_{3}$ and $\mathrm{H}_{2}$ ), and more detailed molecular orbital studies by others $(6,7)$ have predicted that $\mathrm{BH} 5$ is stable by $2 \mathrm{kcal}$ (6) and by $1.7 \mathrm{kcal}$ (7). These estimates seem low by perhaps a factor of 2 or 3 in view of the probable lifetime $(4,5)$ of about $10^{-10}$ sec for loss of $\mathrm{H}_{2}$. All of these theoretical studies fayor the $\mathrm{C}_{s}$ geometry (Fig. I(d)), like that predicted earlier (8) for $\mathrm{CH}_{5}{ }^{+}$.

of course, if the incoming $\mathrm{D}^{+}$converts $\mathrm{BH}_{4}^{-}$to the $\mathrm{C}_{\mathbf{S}}$ structure of $\mathrm{BH}_{5}$ one may expect loss of HD. The experimental evidence is furthermore consistent with a small amount of scrambling in $\mathrm{BH}_{4} \mathrm{D}$, and mechanisms for this process are implicit in the structures of Fig. 1. A study of the pathway (5) indicates that the $\mathrm{C}_{2 \mathrm{v}}, \mathrm{C}_{\mathrm{s}}$ and $\mathrm{C}_{4 \mathrm{v}}$ structures are good transition states for interconversion of the $C_{s}$ structures (Figs. 2 and 3). Barriers pre-<smiles>CCCC</smiles>

Cs

$\mathrm{B}-\mathrm{H}_{3}$ in plane

$\mathrm{H}_{1} \mathrm{H}_{2}$ bisected $\mathrm{H}_{4} \mathrm{H}_{5}$ bisected<smiles>CCCCCC(C)C</smiles>

$\mathrm{C}_{\mathrm{s}}$

$\mathrm{BH}_{1} \mathrm{H}_{2} \mathrm{H}_{4} \quad \mathrm{~B}-\mathrm{H}_{5}$ in plane in plane $\mathrm{H}_{1} \mathrm{H}_{2}$ bisected

$\mathrm{H}_{4} \mathrm{H}_{3}$ bisected

Fig. 2. One plausible pathway for internal rearrangement of $\mathrm{BH}_{5}$ passes through the $\mathrm{C}_{\mathbf{s}}$ intermediate in which $\mathrm{H}_{5}$ and $\mathrm{H}_{3}$ are related to the axial positions of a hypothetical trigonal bipyramid of even higher energy.

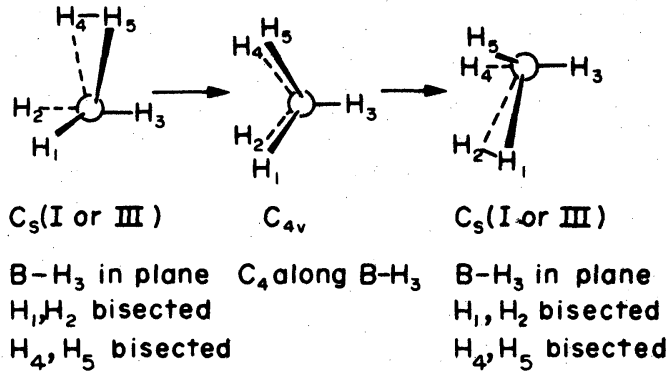

Fig. 3. In the $\mathrm{C}_{4 \mathrm{v}}$ intermediate the equivalent axial positions of the less stable trigonal bipyramidal $\mathrm{BH}_{5}$ are either $\mathrm{H}_{2}$ and $\mathrm{H}_{5}$ or $\mathrm{H}_{1}$ and $\mathrm{H}_{4}$.

dicted for this process at the minimum basis set level are $20 \mathrm{kcal} / \mathrm{mole}$ if the intermediate has $C_{2 v}$ or $C_{s}$ symmetry and $30 \mathrm{kcal} / \mathrm{mole}$ if the intermediate has $\mathrm{C}_{4 \mathrm{v}}$ symetry. Experimental studies of the gas phase exchange of $\mathrm{D}_{2}$ with diborane to yield HD may involve heterogeneous steps (9), but these studies yield an activation energy of about $20 \mathrm{kcal} / \mathrm{mole}$. The H-D exchange in the gas phase reaction of $\mathrm{HBF}_{2}$ with $\mathrm{D}_{2}$ has an activation energy 
of $18 \mathrm{kcal} / \mathrm{mole}(10)$, and probably does proceed through a multicentered molecular orbital between $\mathrm{HBF}_{2}$ and $\mathrm{D}_{2}$.

In predicting which pair of hydrogen atoms is lost from these structures, it is sufficient to refer all to trigonal bipyramidal $\mathrm{BH}_{5}$ of $\mathrm{D}_{3 \mathrm{~h}}$ symetry. Overlap populations are 0.04 e for axial-equatorial, -0.05 e for axialaxial and -0.07 e for equatorial-equatorial pairs of $\mathrm{H}$ atoms. The formation of a chemical bond between two $\mathrm{H}$ atoms proceeds smoothly, without a barrier arising from crossing of molecular orbitals, only between the axial-equatorial pairs. This feature is retained upon distortion to $\mathrm{C}_{4 \mathrm{~V}}$, $\mathrm{C}_{2 \mathrm{v}}$ or $\mathrm{C}_{\mathrm{s}}$ symmetries. For example, in the tetragonal pyramidal $\mathrm{C}_{4 \mathrm{v}}$ structure of Fig. 3 the overlap populations are -0.03 e for basal-axial and 0.08 e for adjacent basal-basal pairs of $\mathrm{H}$ atoms. One result is that if $\mathrm{D}^{+}$enters $\mathrm{BH}_{4}$ along the four-fold axis of this structure and if this $D$ remains uniquely in this position, it is unlikely that HD would be lost in preference to loss of $\mathrm{H}_{2}$ from two adjacent basal positions. Hence, the observed loss of HD leads one to favor two equivalent positions as shown in Fig. 4 .

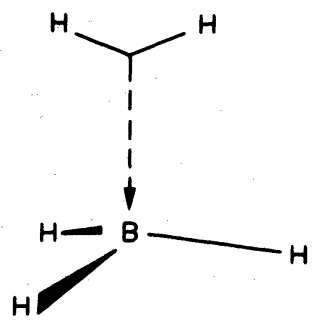

Fig. 4. Simplified valence description of bonding in $\mathrm{BH}_{5}$, showing donation of the $\mathrm{H}-\mathrm{H}$ bond into the vacant orbital of a slightly pyramidal $\mathrm{BH}_{3}$ group.

Very different experimental results are obtained (11) when excess solid $\mathrm{NaBH}_{4}$ is treated with anhydrous $\mathrm{D}_{2} \mathrm{SO}_{4}$ or $\mathrm{DF}$ (or isotopic inverses) in a bomb at $-78^{\circ}$. Essentially statistical results are found, typically almost $608 \mathrm{H}_{2}, 40 \% \mathrm{HD}$ (plus $28 \mathrm{D}_{2}$ ). Perhaps the reaction occurs at a crystal surface, or the $\mathrm{BH}_{4} \mathrm{D}$ may be formed in a state of excess internal energy so that rearrangement is facilitated in these experiments.

Styx formulas for vacant-orbital species

If a neutral boron hydride has formula $\mathrm{B}_{\mathrm{p}} \mathrm{H}_{\mathrm{p}+\mathrm{q}}$, and if there are vacant valence orbitals, then

$$
\begin{array}{ll}
s+x=q & s \text { for } B H B \text { bonds } \\
s+t=p-v & t \text { for } \mathrm{BBB} \text { bonds } \\
t+y=p-q / 2 & y \text { for } \mathrm{BB} \text { bonds } \\
\mathrm{B} \text { - } & \mathrm{x} \text { for } \mathrm{BH}_{2} \text { number }
\end{array}
$$

Thus the number of three-center bonds $s+t$ is reduced by the number of vacant orbitals, but the number of hydrogens $(s+x+p)$ and the number of framework bonds $(t+y)$ remain constant. This idea was introduced in a discussion of $\mathrm{B}_{4} \mathrm{H}_{8}$ by Dupont and Schaeffer (12). For example, formulas for $\mathrm{B}_{4} \mathrm{H}_{8}$ are 4020 , 2202 and 3111 for $v=0,3021,2122$ and 1203 for $v=1$, and 2022, 1113 and 0204 for $v=2$. For $\mathrm{B}_{3} \mathrm{H} 7$ they are 3011 and 2102 for $v=0,2012$ and 1103 for $v=1$, and 1013 and 0104 for $v=2$. These rules are easily extended to charged species, and to heteroatom species.

$\mathrm{B}_{2} \mathrm{H}_{4}$

The 2010 topology has two $\mathrm{BH}$ groups joined by two bridge hydrogens and by a single (pure $\pi$ ) bond. This topologically disallowed structure does have four bonds to each boron, but it is less stable at the minimum basis set (slater orbitals) by over $100 \mathrm{kcal} / \mathrm{mole}$ than either of two conformers of the 0012 topology.

These 0012 structures have two $\mathrm{BH}_{2}$ groups joined by a single $\mathrm{B}-\mathrm{B}$ bond, and therefore each boron has a vacant orbital ( $\pi$ relative to the $\left.\mathrm{H}_{2} \mathrm{~B}-\mathrm{plane}\right)$. We find (13) that the staggered conformer $\left(D_{2 d}\right)$ is more stable by $13 \mathrm{kcal} /$ mole than the eclipsed $\left(D_{2 h}\right)$ conformer. A previous result, at the 6-31G level, also favors $D_{2 d}$ over $D_{2 h}$, by $11 \mathrm{kcal} / \mathrm{mole}(14)$. The staggered conformer has a hyperconjugative interaction between the vacant orbital on each boron with the $\pi$ component of the localized molecular orbital on the adjacent $\mathrm{BH}_{2}$ group. No such stabilizing interaction can occur in the planar $\left(D_{2 h}\right)$ form. 
$\mathrm{B}_{3} \mathrm{H}_{7}$

At the minimum basis set SCF level the 1103 (staggered) structure (Fig. 5) is $12 \mathrm{kcal} / \mathrm{mole}$ more stable than the 2102 structure for $\mathrm{B}_{3} \mathrm{H}_{7}$.

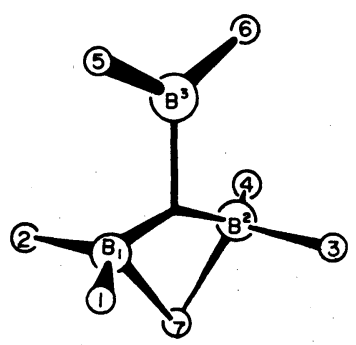

$1103 \mathrm{ST}$
Fig. 5. In the 1103 (staggered) structure for $\mathrm{B}_{3} \mathrm{H}_{7}$ there is a central three-center BBB bond. The less stable 1103 (eclipsed) form has the planar $\mathrm{B}_{3} \mathrm{H}_{5} \mathrm{H}_{6}$ group rotated by $90^{\circ}$ about the $\mathrm{B}_{3} \cdots \mathrm{H}_{7}$ axis which is the molecular two-fold axis.

The 1103 (eclipsed) structure is only $4 \mathrm{kcal} / \mathrm{mole}$ more stable than the 2102 structure. Actually, these structures are very closely related: if $\mathrm{H}_{7}$ is moved away from $\mathrm{B}_{2}$ the 2102 structure is almost that of 1103 (staggered) if we take-identifications as $B_{2}(2102) \longrightarrow B_{3}(1.103 \mathrm{ST})$, and $B_{1}$ or $B_{3}$ of 2102 as $B_{1}$ or $B_{2}$ of 1103 ST. No barrier is found between these structures, so that rearrangements of $\mathrm{H}$ atoms could proceed readily.

Extension of the basis sets to the 4-3lG level and addition of configuration interaction to the minimum slater set widens the energy gap between the 1103 (staggered) and the less stable 1103 (eclipsed) conformers of $\mathrm{B}_{3} \mathrm{H}_{7}$. These extensions make the 1103 (staggered) conformer only slightly more stable than the 2102 conformer, probably owing to the presence of one more bridge hydrogen in the 2102 structure. Electron-electron repulsions within a bridge bond are less than those in a single bond by about $3 \mathrm{kcal} / \mathrm{mole}$ in these conformers, and by about $6 \mathrm{kcal} / \mathrm{mole}$ in the $2 \mathrm{BH}_{3}$ to $\mathrm{B}_{2} \mathrm{H}_{6}$ transformation at the minimum basis level including configuration interaction.

On the other hand the (bent) BHB bond has a strain of about $10 \mathrm{kcal} / \mathrm{mole}$. Hence, the 2102 structure (Fig. 6), which has filled localized orbitals

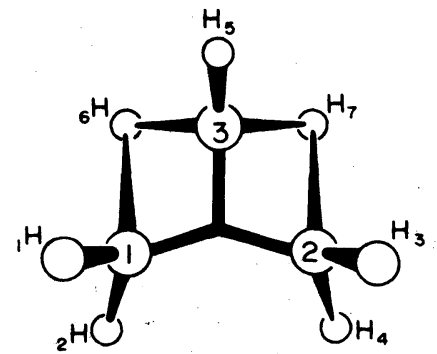

2102
Fig. 6. In the 2102 structure for $\mathrm{B}_{3} \mathrm{H}_{7}$ there is a central three-center BBB bond. Geometrical optimization places $\mathrm{H}_{6}$ and $\mathrm{H}_{7}$ closer to $\mathrm{B}_{3}$ than to $\mathrm{B}_{1}$ and $\mathrm{B}_{2}$, respectively, and makes the structure intermediate between 2102 and $0104 \mathrm{CBH}_{3}$ joined to two $\mathrm{BH}_{2}$ groups by a central three-center $\mathrm{BBB}$ bond).

counting the central three-center BBB bond, is less stable than the 1103 ST structure (Fig. 5), which has at $B_{3}$ a vacant orbital which is only partly filled by the hyperconjugative interaction with the two $\mathrm{BH}_{2}$ units. Thus, in small boron hydrides there is a compromise between structures having a vacant orbital (which orients to hyperconjugate if possible) and structures which fill this vacant orbital by converting a terminal $B H$ bond to a (strained) bridge BHB bond.

$\mathrm{B}_{4} \mathrm{H}_{8}$

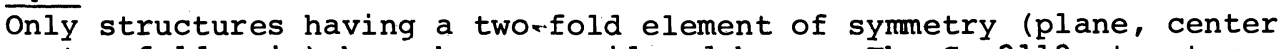
or two-fold axis) have been considered here. The $C_{s} 2112$ structure (Fig. 7), which has one vacant orbital is slightly preferred energetically, as compared to the closely related $\mathrm{D}_{2} \mathrm{~h} 0204 \mathrm{ST}$ structure (Fig. 8) which has two vacant orbitals and no bridge hydrogens. We did not study the intermediate 1203 structure (of $C_{1}$ symmetry) which has one vacant orbital, but it surely lies very close in energy to these two structures.

Here again there is a tendency in a strained structure to leave a vacant orbital. The filled-orbital $C_{2} 2202$ structure actually refined, upon 


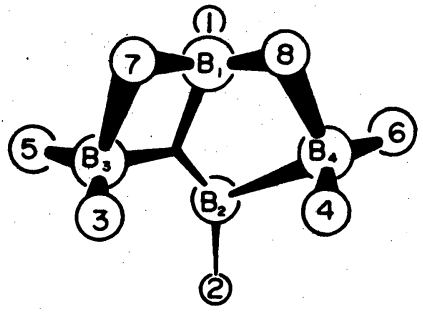

2112

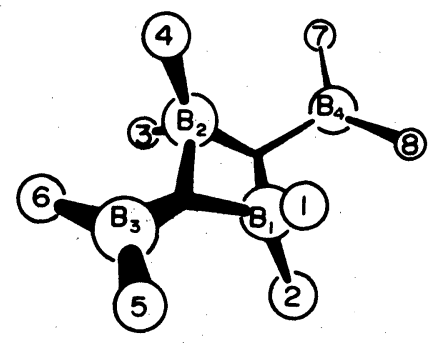

0204 ST
Fig. 7. In the (slightly) preferred $\mathrm{C}_{s} 2112$ structure for $\mathrm{B}_{4} \mathrm{H}_{8}$ there is a resonance hybrid between a valence structure having a single $\mathrm{B}_{2} \mathrm{~B}_{4}$ bond and a central threecenter $\mathrm{B}_{1} \mathrm{~B}_{2} \mathrm{~B}_{3}$ bond, and a valence structure with a single $\mathrm{B}_{2} \mathrm{~B}_{3}$ bond and central three-center $\mathrm{B}_{1} \mathrm{~B}_{2} \mathrm{~B}_{4}$ bond.

Fig. 8. The 0204ST structure for $\mathrm{B}_{4} \mathrm{H}_{8}$ is not preferred over the 2112 structure, but is more stable than the 0204 EC structure (both $\mathrm{BH}_{2}$ groups rotated by $90^{\circ}$ ) by $21 \mathrm{kcal} / \mathrm{mole}$ in our calculations (minimum basis set - CI level).

geometry optimization to a $\mathrm{D}_{2 \mathrm{~h}} 0204$ structure as the bridge hydrogens became more and more asymmetric. In the slightly favored $\mathrm{C}_{\mathbf{s}} 2112$ structure, hyperconjugative factors mostly from $\pi$ orbitals (local) of atomic triads, $\mathrm{H}_{5} \mathrm{~B}_{3} \mathrm{H}_{3}$ and $\mathrm{H}_{4} \mathrm{~B}_{4} \mathrm{H}_{6}$, probably help in stabilizing the vacant orbital on $\mathrm{B}_{2}$ (Fig. 7). In addition, aspects of orbital strain, relating to poor overlap contribute to the relative instability of the filled orbital structure. What we have here is an interplay of opposing tendencies to maximize valency and to minimize geometrical strain in these transient molecules.

\section{VACANT ORBITAL CONTRIBUTIONS IN STABLE SPECIES}

\section{General Comments}

When allowance is made for contributions of vacancy valence structures, we can recognize patterns of bridge hydrogen asymmetries, boron framework distortions, and probable modes of nucleophilic and electrophilic attack. Starting with the standard three-center valence structure, we look for the most satisfactory non-vacancy and vacancy valence structures in which bridges are converted to terminal hydrogens (or vice versa) and in which framework single bonds are converted into central three-center bonds (or vice versa). A new geometry is adopted which reflects a consistent set of displacements, and which is then described as a resonance hybrid of various valence structures.

Criteria for evaluation of the contribution of a given vacancy (or nonvacancy) valence structure in the hybrid are (1) the smallest number of vacant orbitals, (2) the smallest magnitudes of charges, (3) the smallest separation of charges, (4) the closest adherence to topological rules (except for vacancies), and (5) the highest symmetries (perhaps the weakest criterion). As an example of (4), we eliminate all valence structures in which adjacent boron atoms remain unconnected. We turn now to three simple examples.

$\mathrm{B}_{4} \mathrm{H}_{10}$ The displacements of bridge hydrogens toward the BH groups, away from the $\mathrm{BH}_{2}$ groups, and the relatively positive $\mathrm{BH}_{2}$ units (Fig. 9) are features of $\mathrm{B}_{4} \mathrm{H}_{10}$ which are correctly predicted by the vacancy hybrid (Fig. 10). The non-vacancy hybrid structure (Fig. 11) also predicts the correct asymetry of bridge hydrogens, but does not represent the correct direction of charge separations in $\mathrm{B}_{4} \mathrm{H}_{10}$. Also a localized molecular orbital study (15) has indicated that the "single" bond of $\mathrm{B}_{4} \mathrm{H}_{10}$ (Fig. 9) shows donation of $0.19 \mathrm{e}$ to each of the borons of the $\mathrm{BH}_{2}$ groups: this feature is an indication of the extent of contributions of valence structures of Figs. 10 and 11 to the resonance hybrid. 


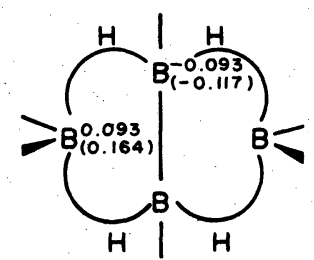

$\mathrm{B}_{4} \mathrm{H}_{10} 4012$

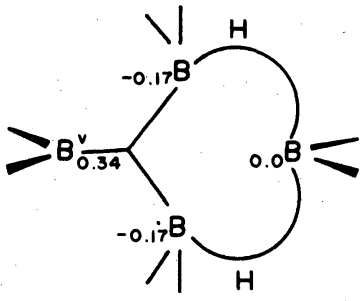

2104
Fig. 9. Charges on $\mathrm{BH}$ and $\mathrm{BH}_{2}$ groups, and in parentheses Mulliken charges on boron in $\mathrm{B}_{4} \mathrm{H}_{10}$.

Fig. 10. The dominant $(\mathrm{v}=1)$ vacancy structure for $\mathrm{B}_{4} \mathrm{H}_{10}$. Bridge hydrogens are displaced towards the $\mathrm{BH}$ groups in this resonance hybrid of two equivalent valence structures.

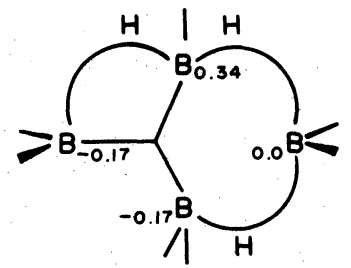

$B_{4} H_{10} 3103$
Fig. 11. A non-vacancy valence structure which also is consistent with displacement of bridge hydrogens toward the $\mathrm{BH}$ groups in $\mathrm{B}_{4} \mathrm{H}_{10}$.

\section{B5H11}

The bridge hydrogen asymmetries, B-B interactions and charge distributions in $\mathrm{B}_{5} \mathrm{H}_{1}$ (Fig. 12) are well given qualitatively by the 2204 pair, the single 1205 and the pair of 3113 vacancy structures of Fig. 13. Examples of vacancy structures, neglected here, which have unsatisfactory charge distributions are shown in Fig. 14. Even the bridging character of the unique hydrogen on the apex boron arises naturally, even though it localizes approximately as a terminal hydrogen (15). This feature is also given by the non-vacancy structure of Fig. 15, but this valence structure does not predict the charge distribution in $\mathrm{B}_{5} \mathrm{H}_{11}$. Turning now to the bonding pattern, the 3113 hybrid (Fig. 13) indicates correctly that the bonding between apical $B$ and the $B H$ groups is stronger than the bonding between apical $\mathrm{B}$ and the $\mathrm{BH}_{2}$ groups consistent with a striking asymmetry (15) of the two central three-center framework bonds of Fig. 12 .

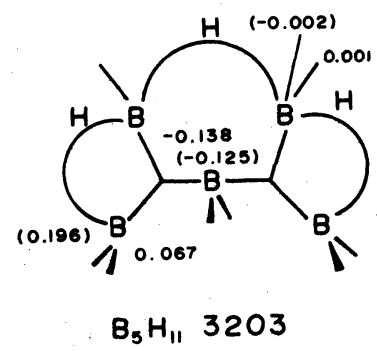

Fig. 12. Charges on $\mathrm{BH}$ and $\mathrm{BH}_{2}$ groups, and in parentheses Mulliken charges on boron in $\mathrm{B}_{5} \mathrm{H}_{11}$. 


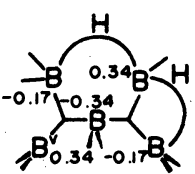

2204

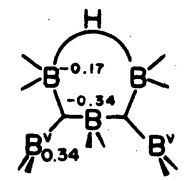

1205

Fig. 13. Dominant $(\mathrm{v}=1)$ vacancy structures for $\mathrm{B}_{5} \mathrm{H}_{11}$. Two bridge hydrogens are displaced towards BH away from $\mathrm{BH}_{2}$ groups, and the unique hydrogen on the apex $\mathrm{BH}$ interacts with either of the two $\mathrm{BH}_{2}$ groups in the resonance hybrid of 3113 topology.

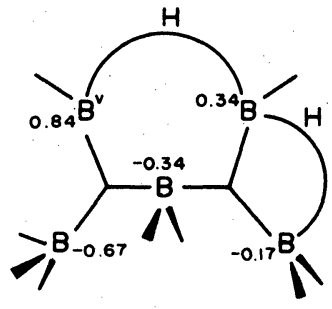

2204

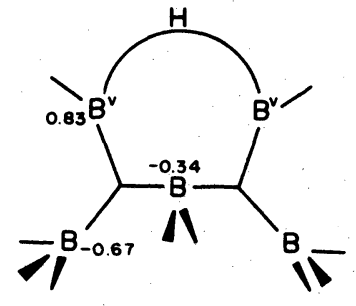

1205
Fig. 14. Vacancy structures for $\mathrm{B}_{5} \mathrm{H}_{11}$ which are neglected because of large atomic charges. Also, vacancy structures are neglected if adjacent borons remain unbonded (not shown).

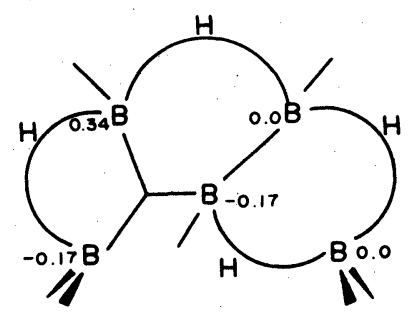

4112
Fig. 15. Non-vacancy structure for $\mathrm{B}_{5} \mathrm{H}_{11}$ which accounts for the unique hydrogen interaction with $\mathrm{BH}_{2}$ groups, but which does not account for other geometrical distortions (unsymmetrical bridges and BB distances).

$\mathrm{B}_{3} \mathrm{H}_{8}^{-}$

The styx equations for a non-vacancy compound $\mathrm{B}_{\mathrm{p}} \mathrm{H}_{\mathrm{p}}^{\mathrm{C}}+\mathrm{q}$ having $\mathrm{BH}, \mathrm{BH}_{2}$ or/and $\mathrm{BH}_{3}$ groups hydrogen, and having charge $c$ are $s+x=q+c, s+t=p+c-v$, and $t+y+q / 2=p-c$. The normal non-vacancy structure is the 2103 structure of Fig. $16(a)$. However, a localized molecular orbital study reveals a substantial interaction $(0.57 \mathrm{e})$ of the single bond along the thin line of Fig. 16(b), leaving 0.74 e toward each B or the original "single" bond. This additional framework bonding displaces the bridge hydrogens away from the apex B as shown in Fig. 16b. This effect is described as a resonance hybrid in which the vacancy structure of Fig. 17 makes an appropriate contribution to the original valence structure of Fig. $16(\mathrm{a})$.

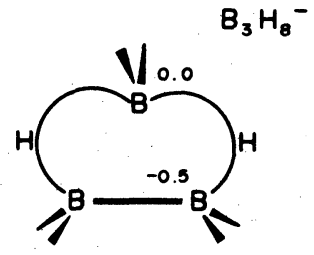

(a) 2013

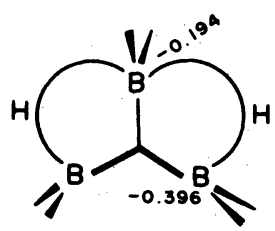

(b) 2103
Fig. 16. Non-vacancy structures for $\mathrm{B}_{3} \mathrm{H}_{8}$ showing the three-center bond structure on the left, and the fractional bond structure on the right. The additional fractional interaction (thin line) tends to make the bridge hydrogens unsymmetrical. 


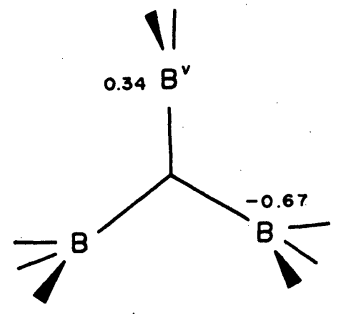

0105
Fig. 17. Vacancy structure for $\mathrm{B}_{3} \mathrm{H}_{8}$ in which the bridge hydrogens are displaced. Compare with Fig. 16.

\section{LOCALIZED MOLECULAR ORBITALS}

General Comments

Molecular orbitals of different symmetries can be linearly combined in such a way that either

$$
\sum \iint \phi_{i}(1) \phi_{i}(1) \frac{1}{r_{12}} \phi_{i}(2) \phi_{i}(2) d v_{1} d v_{2}
$$

is maximized (Edmiston and Ruedenberg (16)), or

$$
\sum \iint \phi_{i}(1) \phi_{i}(1) \quad r_{12}^{2} \phi_{i}(2) \phi_{i}(2) d v_{1} d v_{2}
$$

is minimized (Boys (17)). These procedures have been compared (18) in a number of boranes and carboranes. Without changing the total electron density, these procedures maximize the repulsive interactions of electrons within the same molecular orbital, and therefore approximate the chemists' localized electron pair bond in a totally objective way. In recent studies of all boranes and carboranes of known structures, we have obtained direct support for three-center bond descriptions, more detailed principles of bonding, and in complex examples descriptions which replace a large number of resonance hybrids. We now turn to a few examples.

Open and central three-center bonds

Alternative descriptions of the valence structure of $\mathrm{B}_{5} \mathrm{H}_{11}$ are shown in Fig. 18. The ER localization yields the valence structure of Fig. $18 \mathrm{~b}$ (more precisely that of Fig. $18 \mathrm{~b}^{\prime}$ ), not the open three-center bond shown in Fig. 18a. In all localizations so far obtained by either the ER or Boys procedure, no open three center bond with boron as the central atom has been found. Hence, we no longer employ this description (19).

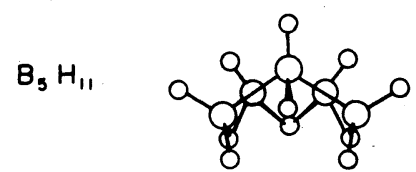<smiles></smiles>

a

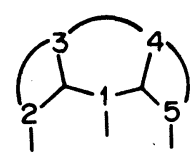

b

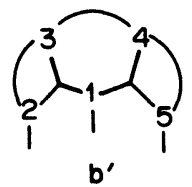

Fig. 18. Structure of $\mathrm{B}_{5} \mathrm{H}_{11}$. (a) Open threecenter bond structure not favored by localization of molecular orbitals. (b) Favored valence structure as conventional central three-center bonds. (c) Decreased interactions of central three-center bonds toward outer $\mathrm{BH}_{2}$ groups, from localized orbitals. One terminal hydrogen has been omitted from each boron atom in the valence structures.

However, an example of a localized (ER procedure) open three-center bond occurs in $1,2-\mathrm{C}_{2} \mathrm{~B}_{4} \mathrm{H}_{6}$. Here, the central atom is carbon (Fig. 19). A comparison of the localization by Boys' procedure is given below. Inasmuch as the charge distribution in the open three-center bond places one electron on the central atom, and one-half on each outer atom, we believe 


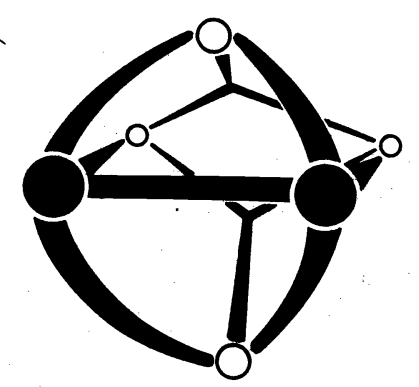

Fig. 19. Open three-center bonds through carbon atoms (black) in $1,2-\mathrm{C}_{2} \mathrm{~B}_{4} \mathrm{H}_{6}$. The six hydrogen atoms have been omitted for simplicity.

that the extra nuclear charge of carbon, over that of boron, favors the open three-center bond over the central three-center bond in some carboranes.

Single bond donation to adjacent atoms. When a single bond occurs within a boron framework like that shown in Fig. 20, the localization procedures usually show additional donations to adjacent atoms. In $\mathrm{B}_{4} \mathrm{H}_{10}$ almost $0.2 \mathrm{e}$ is donated to each of $\mathrm{B}_{1}$ and $\mathrm{B}_{4}$ (Fig. 21), which are partly relatively electron deficient because of the charge distribution in the BHB bridge bonds. These hydrogen bridges then become unsymmetrical, as described above, in such a way that the hydrogens are displaced toward $\mathrm{B}_{2}$ and $\mathrm{B}_{3}$. Two other simple examples are shown (20) in $\mathrm{B}_{8} \mathrm{H}_{13}^{-}$(Fig. 22) and in $\mathrm{B}_{8} \mathrm{H}_{14}$ (Fig. 23). Electron withdrawal along other bonds occurs away from the atom which is the recipient of the single bond donation. This donor property of single bonds is quite general in triangulated polyhedral molecules and their fraqments amona boranes and carboranes.<smiles>[B]C([B])([B])[B]</smiles>

$0.1-0.2 e$<smiles>[B]C([B])([B])[B]</smiles><smiles>[B]C([B])([B])[B]</smiles>

$0.21-0.3 e$<smiles>[B]C([B])([B])[B]</smiles>

$>0.41 \mathrm{e}$

Fig. 20. Symmetrical single bond donation toward adjacent atoms, showing notation for amounts of donation of the original electron pair of the single bond. In many cases, the donation is unsymmetrical.

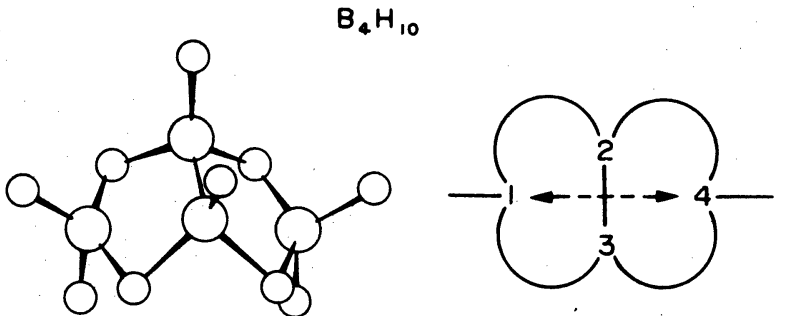

Fig. 21. Donation of 0.19 e to each $\mathrm{BH}_{2}$ group from the "single" bond in $\mathrm{B}_{4} \mathrm{H}_{10}$.

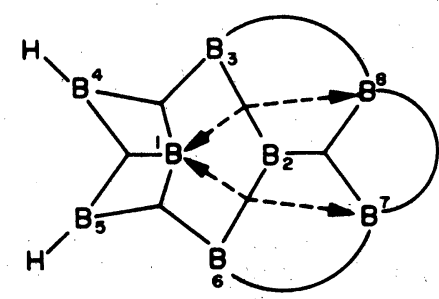

B. $\mathrm{H}_{13}^{-}$
Fig. 22. Single bond donation in $\mathrm{B}_{8} \mathrm{H}_{13}{ }^{-}$. 


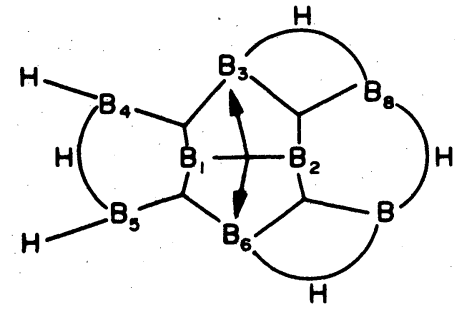

$B_{8} H_{14}$
Fig. 23. Single bond donation in $\mathrm{B}_{8} \mathrm{H}_{14}{ }^{-}$. Usually this donation causes some electron withdrawal along the other bonds to the atom receiving a donation.

Fractional three-center bonds. Electron withdrawal noted above, coupled with single bond donation, often gives rise to another general feature of localized orbitals: fractional three-center bonds (Fig. 24). While fractional bonds (the dotted lines) appear to enlarge the number of bonds at $B_{1}$ (Fig. 24), the exclusion principle is not violated, because of the fractional occupancy of the valence atomic orbitals at $B_{1}$. We note a similar behavior in the carboxylate group (Fig. 25) in order to convince the reader that these fractional bonds are not limited to boron chemistry.

In $4,5-\mathrm{C}_{2} \mathrm{~B}_{4} \mathrm{H}_{8}$ two fractional bonds (21) to $\mathrm{B}_{2}$ are a preferred alternative (Fig. 26) to a resonance hybrid of a single bond (e.g. $\left.B_{1} B_{3}\right)$ and a central three-center bond $\left(e . g \cdot B_{1} B_{2}{ }_{6}\right)$.<smiles>[B]B([B]C1[B]C([B])[B]C1[B])C([B])[B]CC</smiles>

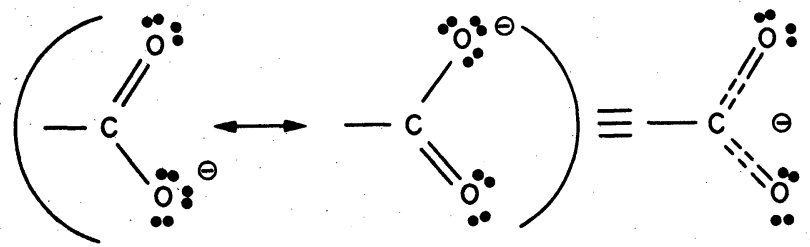

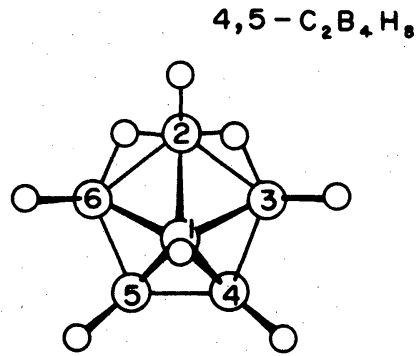

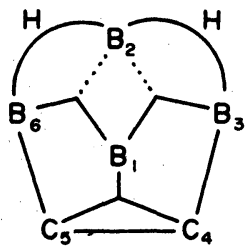

Fig. 24. In the localized molecular orbital description two fractional electron pair bonds (right) replace a resonance hybrid (in parenthesis) of a single bond and a central threecenter bond.

Fig. 25. Localized molecular orbitals in a carboxylate anion, showing four equivalent fractional bonds to carbon from the two oxygens. The equivalent resonance hybrid is in parentheses.

Fig. 26. Localized orbitals in $4,5-\mathrm{C}_{2} \mathrm{~B}_{4} \mathrm{H}_{8}$, showing two equivalent fractional bonds to $\mathrm{B}_{2}$. 
In $\mathrm{B}_{10} \mathrm{H}_{14}$ the same feature of two fractional bonds occurs at $\mathrm{B}_{6}$, and again at $\mathrm{Bg}$ in the preferred description (Fig. 27c). A similar feature occurs in the $\mathrm{B}_{10} \mathrm{H}_{14}{ }^{-2}$ ion, at $\mathrm{B}_{2}$ and $\mathrm{B}_{4}$.

Pairs of fractional bonds are also found by Boys' localization procedure at two boron atoms in $1,2-\mathrm{C}_{2} \mathrm{~B}_{4} \mathrm{H}_{6}$ ( $\left.\mathrm{Fig} .28 \mathrm{~b}\right)$, and at two boron atoms in $1,7-\mathrm{C}_{2} \mathrm{~B}_{10} \mathrm{H}_{12}$ (Fig. 29, right). However, the Edmiston-Ruedenberg localization procedure, which we prefer, yields the alternative of open three-center bonds through each carbon atom in $1,2-\mathrm{C}_{2} \mathrm{~B}_{4} \mathrm{H}_{6}$, and probably would yield the valence structure of Fig. 29 (left) if and when a similar calculation, involving all two-electron integrals, is economically feasible.

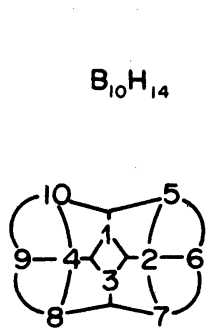

a

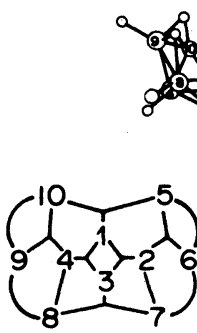

$b(4)$

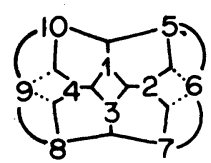

C
Fig. 27. Localized orbitals in $\mathrm{B}_{10} \mathrm{H}_{14}$ showing fractional bonds (c), which are preferred over the four equivalent resonance structures (b), and are much preferred over the nearly equivalent description having open three-center bonds (a). The diagram below shows the essential idea.

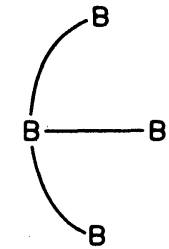

a<smiles>[B]BC([B])[B]</smiles>

$b(2)$<smiles>[B]C1[B]C([B])[B]1</smiles>

c (a)

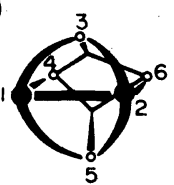

(c)<smiles>[13CH3]CC[13CH3]</smiles>

(b)

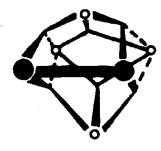

(d)<smiles>[B]C1CPC([B])C1</smiles>

Fig. 28. An ambiguity in localization in $1,2-\mathrm{C}_{2} \mathrm{~B}_{4} \mathrm{H}_{6}$, in which the Edmiston-Ruedenberg procedure yields (a), while the Boys procedure yields (b). The parts of the molecule which differ are idealized in (c) and (d), respectively.
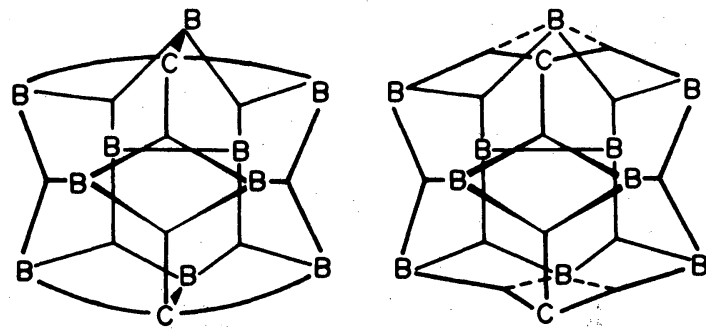

$1,7-\mathrm{C}_{2} \mathrm{~B}_{10} \mathrm{H}_{12}$
Fig. 29. Localization by Boys' procedure (right) gives fractional bonds (dotted lines) in 1,7$\mathrm{C}_{2} \mathrm{~B}_{10} \mathrm{H}_{12}$. The EdmistonRuedenberg procedure would probably give the preferred valence structure (left) having open three-center bonds through carbon. 
The $\mathrm{B}_{5} \mathrm{H}_{9}$ molecule shows an ambiguity in localization which is frequent, and almost typical, in a molecule having an axis of higher than two-fold symmetry. There is actually a continuum of localized structures,

rotationally equivalent by an arbitrary displacement around the high symmetry axis: all of these valence structures are equally preferred (Fig. 30). This continuum of structures is present in the $\pi$ systems of the $4 n+2$ cyclic aromatic molecules $C_{n} H_{n}^{C}$ of appropriate charge (22).

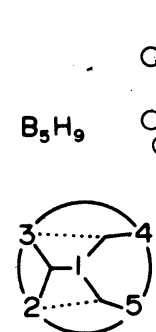

(a)
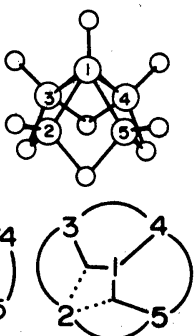

(b)

Fig. 30. Orientational ambiguity in the localized valence structures for the three pairs of electrons in the fourfold $\mathrm{B}_{5} \mathrm{H} 9$ framework orbitals. A continuum of valence structures, all equally preferred, lies between the extremes (a) and (b).

More complex molecules

In $\mathrm{C}_{2} \mathrm{~B}_{10} \mathrm{H}_{13^{-}}$(Fig. 31 ) we have a simple pattern of localization predicted (23) to have little fractional bonding.

The 1,2- $\mathrm{C}_{2} \mathrm{~B}_{10} \mathrm{H}_{12}$ structure (Fig. 32) obtained by Boys' procedure has two fractional bonds at a boron in two places in the molecule, and has a valence structure which is like that of $1,7-\mathrm{C}_{2} \mathrm{~B}_{10} \mathrm{H}_{12}$ except for orientation and identity of atoms.

The next most complex example, iso- $\mathrm{B}_{18} \mathrm{H}_{22}$ (Fig. 33), shows both fractional

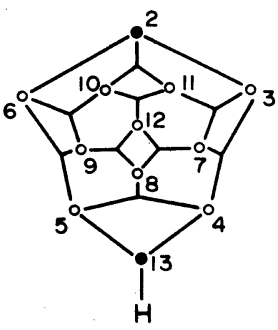

$\mathrm{C}_{2} \mathrm{~B}_{10} \mathrm{H}_{13}^{-}$

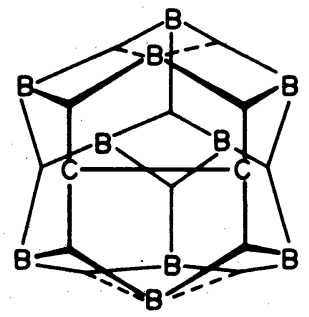

$1,2-\mathrm{C}_{2} \mathrm{~B}_{10} \mathrm{H}_{12}$

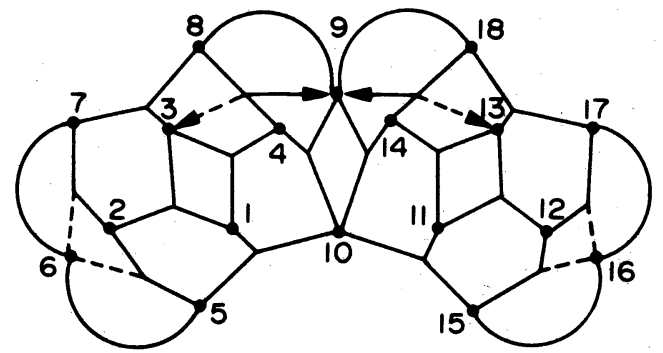

Fig. 31. Localized orbitals in the nearpolyhedral $\mathrm{C}_{2} \mathrm{~B}_{10} \mathrm{~B}_{13}$ ion. This especially simple localization in a complex species shows little significant fractional bonding.

Fig. 32. Localized orbitals (Boys procedure) in $1,2-\mathrm{C}_{2} \mathrm{~B}_{10} \mathrm{H}_{12}$, showing two fractional bonds to each of two boron atoms. Except for identities of atoms (and a back to front orientation) this valence structure is like that for the Boys localization in $1,7-C_{2} \mathrm{~B}_{10} \mathrm{H}_{12}$ (Fig. 29, right).
Fig. 33. The iso- $\mathrm{B}_{18} \mathrm{H}_{22}$ molecule, in which $\mathrm{B}_{10}$ has no terminal hydrogen shows fractional pairs of bonds to $\mathrm{B}_{6}$ and to $B_{16}$, and shows single bond donation from $\mathrm{B}_{4} \mathrm{~B}_{8}$ and from $\mathrm{B}_{14} \mathrm{H}_{18}$ as indicated by arrows. 
bonding, and single bond donation. This single bond donation is greater toward the relatively deficient boron atom $\mathrm{B}_{9}$ which has two bridge hydrogens.

A remarkable example of single bond donation is shown in the localized orbitals of $\mathrm{B}_{20} \mathrm{H}_{16}$ (Fig. 34), where each half of the molecule has clearly the reduced $\mathrm{B}_{10}$ framework of $\mathrm{B}_{10} \mathrm{H}_{14}{ }^{-2}$ (Fig. 35).

A somewhat more complex example is that of $\mathrm{B}_{16} \mathrm{H}_{20}$ (Fig. 36) where the valence structure is dominated by the three-center bonding pattern, modified by single bond donation and by associated electron withdrawal along the dotted legs of the appropriate three-center bonds. However, a new feature is that atoms $\mathrm{B}_{11}$ and $\mathrm{B}_{12}$ are connected only by single bond donation. Even so, the structure is closely related to a more standard three-center bond description: for example, removal of all dashed lines and dashed arrows in the $\mathrm{B}_{6}$ (upper right) fragment leaves single bonds $\mathrm{B}_{10} \mathrm{H}_{16}$ and $\mathrm{B}_{9} \mathrm{H}_{13}$, and leaves central three-center bonds $\mathrm{B}_{11} \mathrm{~B}_{12} \mathrm{~B}_{13}$ and $\mathrm{B}_{11} \mathrm{~B}_{12} \mathrm{~B}_{16}$. Similar adjustments make the bonding in the remainder of the molecule rather like that $(20)$ in $\mathrm{B}_{10} \mathrm{H}_{13}{ }^{-}$, and somewhat like that in $\mathrm{B}_{10} \mathrm{H}_{14}$.

Finally, in $\mathrm{B}_{10} \mathrm{H}_{10}{ }^{-2}$, two unique, non-symmetric localized molecular orbital structures are found (24), corresponding to different bonding patterns. In $\mathrm{B}_{2} \mathrm{H}_{18} \mathrm{H}_{2}^{-2}$ and in photo- $\mathrm{B}_{20} \mathrm{H}_{18}{ }^{-2}$, both of which have fragments like that in $\mathrm{B}_{1} 0^{\mathrm{H}} 10^{-2}$, one of these unigue structures is found in $\mathrm{B}_{20} \mathrm{H}_{18^{-2}}$ and the other in photo- $\mathrm{B}_{20} \mathrm{H}_{18}{ }^{-2}$. The choice of which unique structure occurs is governed by the placement of bridging boron atoms in $\mathrm{B}_{20} \mathrm{H}_{18} 8^{-2}$, and by the positions of the bridge hydrogens in photo- $\mathrm{B}_{20} \mathrm{H}_{18}^{-2}$.

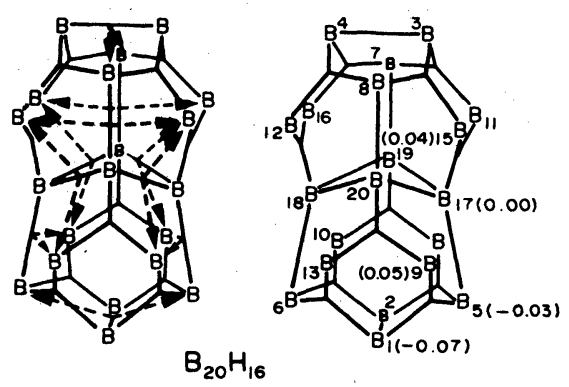

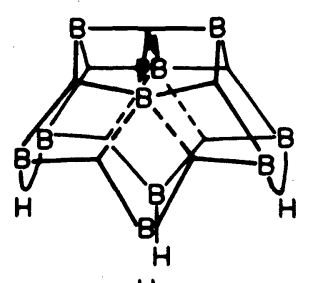

H

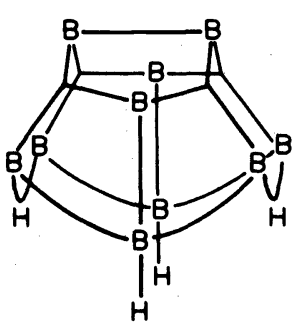

$B_{10} H_{14}=$ (open)
Fig. 34. In $\mathrm{B}_{20} \mathrm{H}_{16}$, where $\mathrm{B}_{17}$, $B_{18}, B_{19}$ and $B_{20}$ have no terminal hydrogens, the nondonation model has a vacant orbital on each of atoms $B_{11}$, $\mathrm{B}_{12}, \mathrm{~B}_{15}, \mathrm{~B}_{16}, \mathrm{~B}_{9}, \mathrm{~B}_{10}, \mathrm{~B}_{13}$ and $B_{14}$ (left). Substantial single bond donation remedies this deficiency, and is also present from single bonds $B_{1} B_{2}$ and $\mathrm{B}_{3} \mathrm{~B}_{4}$ (right).

Fig. 35. Non-donation structure (right) for ${ }^{\mathrm{B}} 10^{\mathrm{H}} 14^{-2}$ having open threecenter bonds, for comparison with the nondonation structure of $\mathrm{B}_{20} \mathrm{H}_{16}$ (right, Fig. 34). The valence structure obtained from localized molecular orbitals is shown on the right for comparison with $\mathrm{B}_{20} \mathrm{H}_{16}$. (left, Fig. 34).

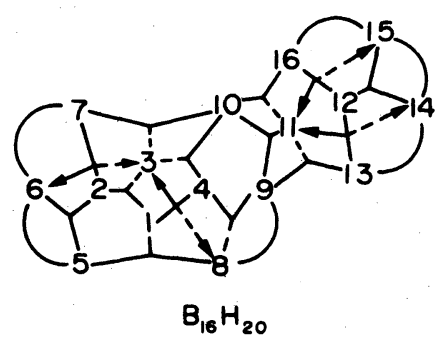

Fig. 36. $\mathrm{B}_{16} \mathrm{H}_{20}$ has a complex pattern of localized molecular orbitals, dominated by single bond donation, as denoted by arrows, accompanied by withdrawal of electrons from atoms $B_{3}, B_{8}$, and $B_{11}$. Note that the solid arrows donating to $B_{11}$ represent the only connection between $B_{11}$ and $B_{12}$. Complex as this pattern is, it replaced the hybrid of 216 central threecenter valence structures by $a$ single preferred valence structure. 


\section{COMMENTS ON REACTIONS}

$\mathrm{BH}_{3}$ addition. In a theoretical study (25) of dimerization of two $\mathrm{BH}_{3}$ molecules to make $\mathrm{B}_{2} \mathrm{H}_{6}$, the symmetrical addition (Fig. 37) was strongly favored over the unsymmetrical formation of one $\mathrm{H}_{2} \mathrm{BH} \cdots \mathrm{BH}_{3}$ bridge.

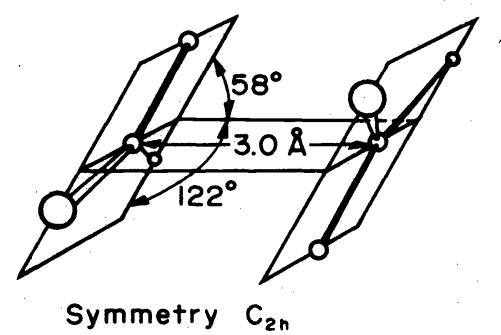

Fig. 37. Geometry of approach of two $\mathrm{BH}_{3}$ units to make $\mathrm{B}_{2} \mathrm{H}_{6}$. At this stage the distortion of $\mathrm{BH}_{3}$ is not very great. As the hydrogen closest to the other boron begins to donate electrons, there is simultaneous donation from the symmetrically related closest hydrogen to the other boron atom.

This unfavorable unsymmetrical addition appears to be rather like the weak addition of $\mathrm{H}_{2}$ to $\mathrm{BH}_{3}$ in order to form $\mathrm{BH}_{5}$ as discussed above. Symmetrical addition is favored, in our interpretation, because, as donation of electrons occurs along one $\mathrm{B} \cdot \cdots \mathrm{H}$ approach, a reverse donation occurs along the symmetrically related $\mathrm{H} \cdot \cdots \mathrm{B}$ approach between different $\mathrm{BH}_{3}$ groups.

Addition of $\mathrm{BH}_{3}$ to transient species, such as $\mathrm{B}_{3} \mathrm{H}_{7}$ or $\mathrm{B}_{4} \mathrm{H}_{8}$ is probably analogous, yielding $\mathrm{B}_{4} \mathrm{H}_{10}$ and $\mathrm{B}_{5} \mathrm{H}_{11}$. Moreover, a similar addition of $\mathrm{BH}_{3}$ to more stable boron hydrides can be envisioned with the use of the dominant vacant orbital valence structures. If we assume that $\mathrm{BH}_{3}$ adds to a pair of boron atoms, one of which has a vacancy, such that vacancy structures yield a dipole whose groups charges are large, then predicted sites of addition are shown in Table 1 . Steric factors, more complex reaction pathways and other factors have not yet been taken into account. Similarly, when vacancy structures place a large positive group charge on one boron it is a candidate for ligand, e.g. hydride ion, attack (Table 1). This simple use of vacancy structures will be examined in more detail in a forthcoming publication (26). 
Table 1. Sites ${ }^{a}$ for predicted addition reactions from vacant orbital theory

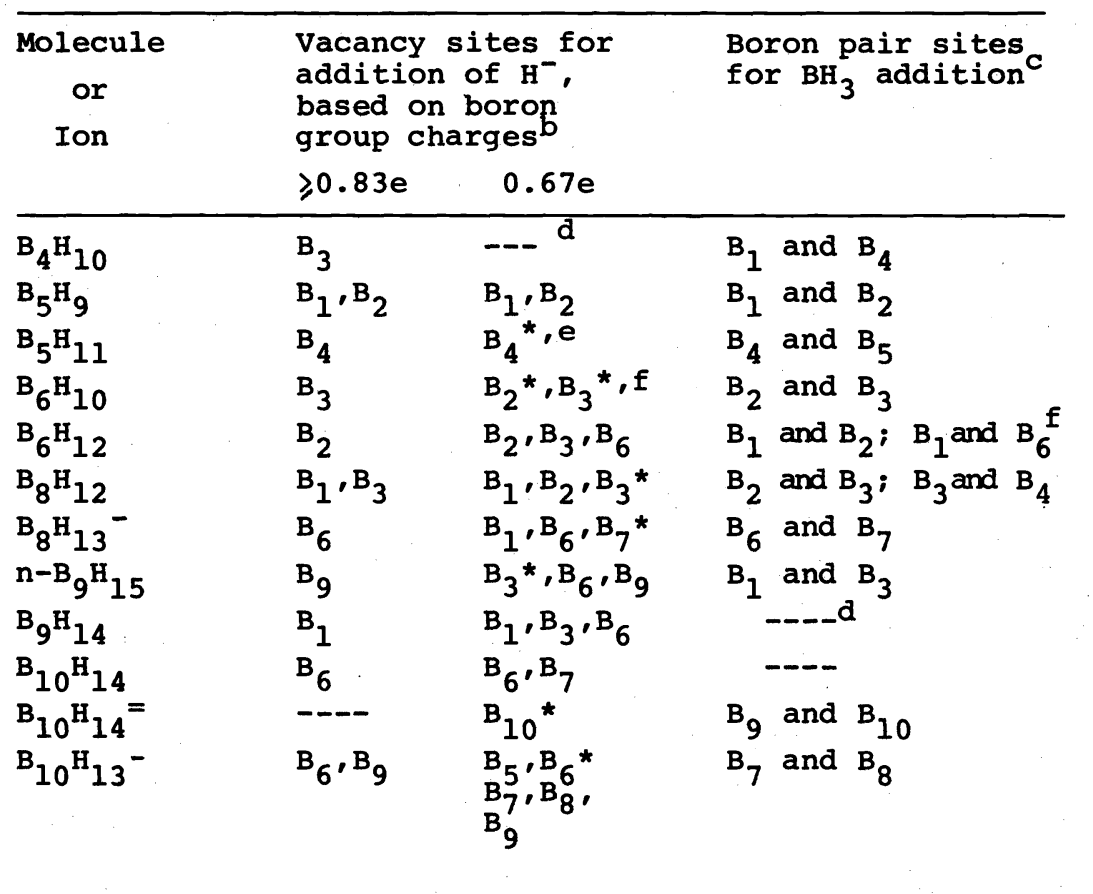

a Unique sites only are given. The unconventional numbering is that of Epstein and Lipscomb, Reference 19.

b

Hydride ion attack may occur at the boron for which (before $\mathrm{H}^{-}$is added) a vacancy structure predicts a vacant orbital and a positive charge of at least $+0.83 e$, regardless of the charge on the boron in the companion non-vacancy structure. Because addition may also be likely at sites with less extreme charges, we also report vacancy sites which exhibit charges of $0.67 \mathrm{e}$.

C $\mathrm{BH}_{3}$ addition is predicted to occur between a pair of borons which, in a vacancy structure, includes one vacancy center, and whose charges represent a dipole of at least $\pm 0.67 e^{-}$.

d A dashed line indicates that no sites are favored for aádition.

e Those sites marked by an asterisk(*) are part of boron pair sites for $\mathrm{BH}_{3}$ addition. They may be less favored for $\mathrm{H}^{-}$addition because of their proximity to a $-0.67 \mathrm{e}$ charge on a neighboring boron.

f Where more than one site exists, the borons are listed in numerical order, not in order of probability of addition. 
Acknowledgement - Most of this research was supported by the Office of Naval Research. I wish to thank Jean Evans for the drawings. For assistance in this research I wish to thank David A. Dixon, Irving R. Epstein, Thomas A. Halgren, John H. Hall, Jr., Daniel A. Kleier, Dennis S. Marynick and Irene $M$. Pepperberg.

\section{REFERENCES}

1. R.A. Hegstrom and W.N. Lipscomb, J. Chem. Phys. 45, 2378-2383 (1966); 48, 809-811 (1968); Rev. Mod. Phys. 40, 354-358 (1968).

2. S. Geller, J. Chem. Phys. 32, 1569-1570 (1960).

3. A. Kaldor and R.F. Porter, J. Am. Chem. Soc. 93, 2140-2145 (1971).

4. M.M. Kreevoy and J.E.C. Hutchins, J. Am. Chem. Soc. 94, 6371-6376 (1972).

5. I.M. Pepperberg, T.A. Halgren and W.N. Lipscomb, J. Am. Chem. Soc., in press, 1976 .

6. C. Hoheisel and w. Kutzelnigg, J. Am. Chem. Soc. 97, 6970-6975 (1975).

7. J.B. Collins, Paul v.R. Schleyer, J.S. Binkley, J.A. Pople and L. Radom, J. Am. Chem. Soc., in press, 1976.

8. P.C. Hariharan, W.A. Latham and J.A. Pople, Chem. Phys. Lett. 14, 385-388 (1972).

9. P.C. Maybury and W.S. Koski, J. Chem. Phys. 21, 742-747 (1953).

10. P.M. Curtis and R.F. Porter, Chem. Phys. Lett. 37, 153-155 (1976).

11. G.A. Olah, P.W. Westerman, Y. K. Mo and G. Klopman, J. Am. Chem. Soc. $94,7859-7862$ (1972).

12. J.A. Dupont and R. Schaeffer, J. Inorg. Nucl. Chem. 15, 310-315 (1960).

13. I.M. Pepperberg, T.A. Halgren and W.N. Lipscomb, Inorg. Chem., in press.

14. J. Dill, P. V.R. Schleyer and J.A. Pople, J. Am. Chem. SoC. 97 , 3402-3409 (1975).

15. E. Switkes, W.N. Lipscomb and M.D. Newton, J. Am. Chem. Soc. 92, 3847-3853 (1970).

16. C. Edmiston and $K$. Ruedenberg, Rev. Mod. Phys. 35, 457-465 (1963).

17. S.F. Boys, Quantum Theory of Atoms, Molecules and the Solid State, (P.0. Lowdin, Ed.), Academic Press, New York (1966), p. 253-262.

18. D.A. Kleier, T.A. Halgren, J.H. Hall, Jr. and W.N. Lipscomb, J. Chem. Phys. 61, 3905-3919. (1974).

19. I.R. Epstein and W.N. Lipscomb, Inorg. Chem. 10, $1921-1928$ (1971).

20. J.H. Hall, Jr., D.A. Dixon, D.A. Kleier, T.A. Halgren, L.D. Brown and W.N. Lipscomb, J. Am. Chem. Soc. 97, 4202-4213 (1975).

21. D.S. Marynick and W.N. Lipscomb, J. Am. Chem. Soc. 94, 8692-8699 (1972). 22. D.A. Kleier, D.A. Dixon and W.N. Lipscomb, Theoret. Chim. Acta 40 ,

23. E.I. Tolpin and W.N. Lipscomb, Inorg. Chem. 12, 2257-2262 (1973).

24. D.A. Dixon and W.N. Lipscomb, J. Am. Chem. SOC., in press.

25. D.A. Dixon, I.M. Pepperberg and W.N. Lipscomb, J. Am. Chem. Soc. 96, 1325-1332 (1974).

26. I.M. Pepperberg and W.N. Lipscomb, to be published. 